\title{
The Impact of Organizational Change on Change Management in ICT sector in the Republic of Croatia
}

\author{
Ivana Sataić
}

Independent Researcher, Polica znanja Ltd. Nova cesta 60, 10000 Zagreb, Croatia

ARTICLE INFO

Keywords:
Organizational Changes
Change Management
ICT
ICT Sector
ADKAR

\begin{abstract}
In recent years, the information and communication technology (ICT) sector has recorded rapid growth and development and is the driving force of the Croatian economy. At the same time, this sector is characterized by fast and dynamic changes which in the demanding business environment requires an immediate and adequate response, so the question of how organizational changes affect change management in ICT sector in the Republic of Croatia arises. To answer this question, empirical research was conducted. The research sample is structured according to data collected from 103 experts in Croatian ICT sector. It offers sufficient elements to establish a quality methodological framework to monitor the impact of organizational change on change management in this sector. This empirical research offered evidence on the possibility of using the ADKAR model of change management in analysis of need for change, implementation, and monitoring of the course of change in ICT organizations. The research results point to the conclusion that organizational change presented through ADKAR model has an impact on change management and is of key importance for ICT organizations. This paper contributes to a better understanding of organizational change and its significance for change management in Croatian ICT organizations.
\end{abstract}

\section{Introduction}

Change management was defined by Morgan and Brightman $(2001,11)$ as a process of continuously renewing the direction, structure, and ability of an organization to serve the needs of external and internal users who are constantly changing. Burnes (2004) sees change as an ever-present feature of organizational life, both at the operational and strategic levels. To understand what ICT sector is, the operational definition of ICT sector considers the standard distinction between products and services but does not include the following sectors: magnetic and optical media manufacturing and the ICT trading industry. Finally, ICT services are grouped into two sub-sectors: telecommunications and computer and related activities (European Commission, Predict 2018).

Information and communication technologies are a global business today. They are constantly, and strongly influenced by the changing business environment. This is why it is important for ICT sector to rapidly respond to every change and ensure an adequate and timely change management in ICT organizations. The goal is to achieve profit growth and in a such way the

\footnotetext{
* Corresponding author E-mail address: ivana.sataic@gmail.com of Applied Research in Management and Economics, 4(1), 60-70. https://doi.org/10.33422/ijarme.v4i1.619
} 
growth of the entire economy. Thus, change management is very important for every ICT organization. In recent years, ICT sector had exceptional results in Croatian economy, which positively reflected in other industries, too. These results indicate that ICT sector can initiate changes in Croatian economy. The necessary prerequisite for that is a quick response to change as ICT organizations face increasing market challenges and trends driven strongly by globalization processes particularly reflected in this sector. One of the most important issues in considering change is related to the change management role in doing business. Change management, which enables quick, timely and adequate response to changes in the organization, is a key element in modern business.

The theoretical elaboration of the impact of organizational change on change management begins with the conceptualization of organizational change with a brief overview of ADKAR as a reference model for measuring and determining organizational change. Given the importance of organizational change, Senior (2002) emphasizes the importance of change management in terms of a very demanding managerial skill. ADKAR offers simple, common concepts within a framework that is easy to understand and implement in everyday situations. Using ADKAR as a common language not only provides clarity and ease of communication but can also positively impact the results of change initiatives and better results of organizational change (Prosci Inc., 2017, 5-6). It is followed by the conceptualization of ITIL model as the most commonly used reference model in change management strategies in ICT sector. According to Schütte (1998) the object of modeling is the management of IT services and the language of description in natural language, while the nature of recommendations, which by definition must exist for reference models, derives from the description of the boundary standard in the field of IT services management. In its approach, ITIL emphasizes the importance of IT management and strategic management in order to achieve the full functionality of the process and the use of information technology through quality services. According to Addy $(2007,186)$ ITIL defines change even more specifically as a process of moving from one defined state to another. Thus, change management enables organizations to implement an effective and efficient process to identify, plan, and manage change in their infrastructure. This study investigates organizational change and change management as comprehensive object factors of business success. Finally, the presented results of the study explain the question of the impact of organizational change on change management in ICT sector in the Republic of Croatia.

\section{From Organizational Change to Change Management in ICT Sector}

\subsection{ADKAR Change Management Model}

ADKAR change management model is one of the latest models applied in change management. It was created in 1998 by the founder of Prosci, Jeff Hiatt. ADKAR model is oriented towards the goals to be achieved in the management of organizational change. The acronym ADKAR comes from the five steps of the change management process that make it successful: Awarness, Desire, Knowledge, Ability, Reinforcement.

According to Hiatt (2006, 2-3) awareness represents an understanding of the nature of change, why change is implemented, and why risk does not change. Awareness also includes information about the internal and external driving forces that created the need for change. Desire represents a willingness to support and engage in change. Knowledge is the information, training and education needed to acquire the skills on how to implement change. Knowledge includes information about behaviors, processes, tools, systems, skills, roles, and techniques needed to implement change. Ability is the realization or implementation of a change. Ability is turning knowledge into action. It is achieved when a person or group has a proven ability to implement change at the required levels of performance. Reinforcement represents those internal and external factors that sustain change. External factors may include recognitions, 
awards, and celebrations while internal factors can be a person's inner satisfaction with achievement or other benefits resulting from a change. Prosci Inc. (2017) identify the standard business factors of a typical change project as: a) identifying a business need or opportunity, b) defining the project (scope and goals), c) creating a business solution (new processes, systems, and organizational structures), d) developing new processes and systems, e) implementing solutions into the organization. These are measurable, concrete aspects of the change project and are usually the default steps when implementing a new solution. ADKAR change management model is an effective tool for planning change management activities and providing support during the change process in organization. It can be used to ensure the success of the transition plan and developing entrepreneurial mindset in ICT sector.

\subsection{ITIL Change Management Model}

ITIL is an acronym for Information Technology Infrastructure Library and represents the most well-known framework for managing IT services. It was created in the late 1980s as a practical set of recommendations and practices in the management of IT services in the world, which today means that IT equipment and services are harmonized with the ITIL methodology (White and Greiner, 2019).

In its approach, ITIL emphasizes the importance of IT management and strategic management in order to achieve the full functionality of the process and the use of technology information through quality services. Thus, ITIL includes best practices in the provision, management, and also change management related to IT services. The ICT sector is constantly evolving, which means that it is necessary to ensure the best quality of IT services and improve business strategies. In change management, the main goal of ITIL is to provide standard methodology and procedures for change planning and management in order to reduce downtime in IT business and ensure adequate quality of IT services. In this context, change management can be defined as the systematic planning and implementation of defined work packages to achieve a predetermined desired outcome or condition.

In ITIL, change is understood as a process of moving from one defined state to another. Change management enables organizations to implement an effective and efficient process to identify, plan, and manage change in their infrastructure. Users need to be provided with functionality to identify and mitigate risks associated with change and to implement them with confidence. Task management and monitoring allow organizations to monitor the change process and identify deviations from the plan at an early stage, and also to take correction activities and create a new schedule to ensure that change stays on the planned path. ITIL could be considered as a standard change model in ICT organizations. Standard change models should rarely be used for anything other than the simplest changes. They should be viewed as auxiliary tool for managers who are responsible for change management. This tool enables the managers to achieve goals according to specifics of the job and work tasks. It is crucial that the plan is created and reviewed in terms of the current environment and current operational capabilities of the IT function to be justified (Addy, 2007).

Consideringall the above, the main hypothesis of this study is as follows: Organizational change has a positive impact on change management in ICT sector.

Additionally, the relationship between organizational changes and change management may be further considered. Accordingly, two additional subhypotheses are established as follows: 1st subhypothesis: Encouraging change in organization has a positive impact on change management in ICT sector.

2nd subhypothesis: Reifnorcement change in organization has a positive impact on change management in ICT sector. 


\section{Explanation of Methodology and Research}

\subsection{Research Sample}

The purpose of the empirical research presented in this paper is to provide better insight into the relationship between organizational change and change management in ICT organizations. The sample of this research covered all organizations of the ICT sector in the Republic of Croatia. The sample was selected at random, somewhat conditioned by the availability of email addresses to which a request to participate in this research was sent. The research was conducted through an online questionnaire in the first half of 2019. 103 respondents filled the questionnaire. The rate of return was about $20 \%$ (19.8\%). There was an equal share of microorganizations and large organizations, which together makes the majority of $68 \%$, while the smallest share is of medium-sized organizations (13\%), as shown in Table 1.

Table 1.

Size of the organizations that participated in the research

\begin{tabular}{lcc}
\hline \multicolumn{1}{c}{ Organization type } & Total number of organizations & Relative frequency \\
\hline Micro & 35 & 34,0 \\
Small & 20 & 19,4 \\
Medium & 13 & 12,6 \\
Large & 35 & 34,0 \\
$\sum$ & $\mathbf{1 0 3}$ & $\mathbf{1 0 0 , 0}$ \\
\hline
\end{tabular}

Source. Authors' own research

The main industry of all organizations in the sample is the ICT service industry. Respondents themselves answered the question about the main activity of their organization. According to the operational definition of ICT sector, the following distribution was obtained (see Table 2):

Table 2.

The main activity of the organizations that participated in the research

\begin{tabular}{lcc}
\hline \multicolumn{1}{c}{ Main activity } & Total number of organizations & Relative frequency \\
\hline Telecomunications & 31 & 30,1 \\
Software publishing & 23 & 22,3 \\
Computer programming, consultancy, related & 19 & 18,4 \\
activities & 11 & 10,7 \\
Computers and related activities & 8 & 7,8 \\
Repair of computers and communication & 6 & 5,8 \\
equipment & 5 & 4,9 \\
Web design & $\mathbf{1 0 3}$ & $\mathbf{1 0 0 , 0}$ \\
Hosting, web portals & & \\
\hline
\end{tabular}

Source. Authors' own research

There was $68.9 \%$ of men in the sample, while $31.1 \%$ of respondents were women. The youngest respondent was 21 and the oldest was 57 years old. The distribution of respondents by age was highly symmetrical, so the median was almost equal to arithmetic mean, the value of which was 35 . The lowest level of education of the respondents was high school with a share of slightly more than a quarter, $26.2 \%$. A very similar share, $27.2 \%$ of respondents graduated from college. The largest share of respondents had higher education or faculty, $44.7 \%$. The average number of work experience of respondents in the main activity of the company was 9.33 years. However, $51 \%$ of respondents had up to 7 years of work experience. Among those who had more than 7 years of work experience in the ICT industry was $11.8 \%$ of those with 15 years and $9.8 \%$ of those with 20 years of ICT work experience. Most respondents, $68.9 \%$, were not managers or they did not have any employees to directly manage, while $7.8 \%$ of them managed one employee. The remaining $22.3 \%$ of respondents 
with an equal share managed 2 to 15 employees, and exceptionally one respondent directly managed 119 employees $(1.0 \%)$. This respondent was working in a software development company with a total number of 120 employees, so he was obviously manager of the entire company.

\subsection{Research Methodology}

The major research variables are explored in this study: organizational changes and change management. When measuring the determinants of the change management in this empirical research, as in previous research (Varkey \& Antonio, 2010; Tudor, 2014), the theoretical approach of the ADKAR model is used. Factors of organizational change included awareness of the need for organizational change, desire to support organizational change, knowledge of how to change the organization, the ability to demonstrate new skills and behaviors to change the organization and reinforcement change in the organization. The ITIL model is used as an indicator of change management, which according to Addy $(2007,187)$ consists of the following structural indicators of change management in the ICT sector: review requirements/identify goals, formulate high level plan, obtain approval to proceed, define tasks and dependencies, conduct risk assessment and back-out planning, define success criteria, assign resources and produce equipment/materials, schedule and perform change/tasks, monitor and track task progress, validate completed change, implement change into production/return to service, review actual change against plan, document discrepancies, update $\mathrm{CMDB}$ /asset repository and close change request. Content validity of both instruments was confirmed by conducting a systematic literature analysis and also through the use of items from some of the most commonly used measure instruments for organizational change and change management. The respondents assessed the importance of individual elements of both measurement scales on the Likert scale from 1 to 5 , where 1 meant complete disagreement and 5 complete agreement. For both measurement scales, the Cronbach's alpha coefficient was calculated to determine their reliability. If the reliability of the measurement scale was determined as insufficient, the next step was to determine claims that affect the decrease in the value of Cronbach's alpha coefficient and at the same time reduce the reliability of the measurement scale. The final version of Cronbach's alfa coefficients for the organizational change measurement scales is shown in Table 3.

Table 3.

Cronbach's alpha coefficients for the organizational change measurement scales

\begin{tabular}{lc}
\multicolumn{1}{c}{ Category of organizational change } & Cronbach's alpha coefficient \\
\hline Awareness & 0,91 \\
Desire & 0,81 \\
Knowledge & 0,79 \\
Ability & 0,71 \\
Reinforcement & 0,80 \\
\hline
\end{tabular}

Source. Authors' own research

Cronbach's alpha coefficient for the overall scale as well as for all five scales of this coefficient was high and suggested the reliability of the measurement scale. In addition, all five scales of Cronbach's alpha coefficients were greater than 0.7 , indicating acceptable or even very good internal reliability consistency of scales.

After determining the reliability of the measurement scales, an exploratory factor analysis was performed to assess their convergent and discriminant validity. The principal components method was chosen, with orthogonal vector rotation (Varimax). As a criterion for selecting the number of latent variables (factors), the Kaiser-Guttman rule of retaining all factors whose eigen value is greater than 1 was applied. The first implementation of the exploratory factor analysis eliminated 4 factors that explained $64.2 \%$ of the variance. A number of "problematic" variables was observed, the communality of which was equally divided into two or more factors, none of which was higher than 0.6. To further refine the measurement scale, the variables were excluded from the factor 
analysis in the following few steps, using several criteria at the same time: a) the variable had no factor load greater than 0.6 on any factor, b) the variable had equally low factor loads on several factors, c) the variable was the only one that explains a certain factor with a high factor load. In the fifth implementation of factor analysis, a satisfactory factor structure with two separate factors was obtained, which explained $75.5 \%$ of the variance as it is shown in Table 4.

Table 4.

Organizational change factor's structure

\begin{tabular}{|c|c|c|}
\hline Claim (factor) & $\begin{array}{c}\text { Factor } 1- \\
\text { Encouraging } \\
\text { organizational change }\end{array}$ & $\begin{array}{c}\text { Factor } 2 \text { - Reinforce } \\
\text { organizational } \\
\text { change }\end{array}$ \\
\hline $\begin{array}{l}\text { Your organization discusses current needs for change in the } \\
\text { organization. }\end{array}$ & 0.870 & \\
\hline $\begin{array}{l}\text { Your organization discusses potential opportunities for } \\
\text { change in the organization. }\end{array}$ & 0.868 & \\
\hline $\begin{array}{l}\text { Your organization encourages reasonable resolution of non- } \\
\text { traditional ideas and activities. }\end{array}$ & 0.806 & \\
\hline $\begin{array}{l}\text { Those who implement change are recognized and rewarded } \\
\text { in your organization. }\end{array}$ & & 0.816 \\
\hline $\begin{array}{l}\text { Your organization encourages and maintains the process of } \\
\text { change through new projects, topics, or employees. }\end{array}$ & & 0.832 \\
\hline $\begin{array}{l}\text { Your organization encourages and maintains the process of } \\
\text { change through new projects, topics, or employees. }\end{array}$ & & 0.800 \\
\hline
\end{tabular}

Table 5 contains the eigen values of the factors and the percentage of explained variance. The results of the factor analysis suggest that the applied measurement scales had the properties of convergent and discriminant validity, given that the corresponding claims had a high factor load on only one factor and low factor loads on the other factor.

Table 5.

Eigen values and percentage of explained variance (organizational change)

\begin{tabular}{ccccc}
\hline Factor & $\begin{array}{c}\text { Eigen } \\
\text { value }\end{array}$ & $\begin{array}{c}\text { Cumulative eigen } \\
\text { value }\end{array}$ & $\begin{array}{c}\text { Percentage of explained } \\
\text { variance }\end{array}$ & $\begin{array}{c}\text { Cumulative percentage of } \\
\text { explained variance }\end{array}$ \\
\hline 1 & 2.300 & 2.300 & 38.339 & 38.339 \\
2 & 2.228 & 4.528 & 37.131 & 75.470 \\
\hline
\end{tabular}

Source. Authors' own research

Furthermore, for the purpose of testing hypotheses using the method of multiple linear regression, the variable "Organizational changes" was created by summing the results of respondents on both factors of organizational change, where the results were weighted by the share of each factor in the total explained variance. Descriptive statistics of this variable can be found in the last row of Table 6 .

Table 6.

Descriptive statistics of attitudes towards organizational changes

\begin{tabular}{cccccccc}
\hline Variable & $\mathbf{N}$ & $\begin{array}{c}\text { Arithmetic } \\
\text { mean }\end{array}$ & Min. Max. & $\begin{array}{c}\text { Std. } \\
\text { deviation }\end{array}$ & Skewness & Kurtosis \\
\hline $\begin{array}{c}\text { Encouraging organizational } \\
\text { change }\end{array}$ & 103 & 5.6892 & 3.06 & 7.65 & 1.15761 & -0.411 & -0.342 \\
$\begin{array}{c}\text { Reinforcement organizational } \\
\text { change }\end{array}$ & 103 & 4.9476 & 2.94 & 7.35 & 0.82198 & 0.772 & 0.469 \\
$\begin{array}{c}\text { Organizational change } \\
\text { Organch }\end{array}$ & $\mathbf{1 0 3}$ & $\mathbf{1 0 . 6 3 6 8}$ & $\mathbf{6 . 0 0}$ & $\mathbf{1 4 . 5 1}$ & $\mathbf{1 . 7 8 7 1 9}$ & $\mathbf{- 0 . 0 7 4}$ & $\mathbf{- 0 . 0 5 4}$ \\
\hline
\end{tabular}

Source. Authors' own research 
From the results shown in Table 6, values of the Skewness coefficient and the Kurtosis coefficient were within the limits of acceptability. Absolute value of the asymmetry coefficient was less than $+/-3$, and the roundness coefficient was less than 10. As collected data did not show an unacceptable level of univariate normality, the variable "Organizational change" was used in further analysis.

The analysis of data collected by "Changes in the ICT sector" scale was approached in the same way. The Cronbach's alpha coefficient was used as an indicator of the reliability of the measuring instrument. The corresponding Cronbach's alpha coefficient for this measure scale is given in Table 7.

Table 7.

Cronbach's alpha coefficients for the change management in ICT sector measurement scales

\begin{tabular}{l|c}
\hline \multicolumn{1}{c|}{ Category of change management } & Cronbach's alpha coefficient \\
\hline Changes in ICT sector & 0,95 \\
\hline
\end{tabular}

Source. Authors' own research

Table 7 shows that the scale "Changes in the ICT sector" has excellent reliability. The influence of individual claims on the overall Cronbach's alpha coefficient was also analysed to identify how much each of them affects the achieved level of reliability. After determining the reliability of the measurement scales, an exploratory factor analysis was performed to obtain optimal linear combinations of manifest variables from the measurement scale "Changes in the ICT sector", which will later be an integral part of the latent variable "Change Management".

The first implementation of the exploratory factor analysis eliminated 2 factors that explained $77.6 \%$ of the variance. A number of "problematic" variables were observed, whose communality was equally divided into two factors, with both factor loads being less than 0.7. In order to further refine the measurement scale obtained by retaining certain variables after performing the reliability analysis, the variables were excluded from the factor analysis. In the second step of the factor analysis by the principal components method, with Varimax rotation and application of the Kaiser-Guttman rule, a satisfactory factor structure was obtained with two separate factors, which explained $81.2 \%$ of the variance. The factor structure is shown in Table 8 .

Table 8.

Change management in ICT sector factor's structure

\begin{tabular}{lcc}
\hline \multicolumn{1}{c}{ Claim (factor) } & $\begin{array}{c}\text { Factor 1 - Planning and } \\
\text { implementation of change }\end{array}$ & $\begin{array}{c}\text { Factor 2 - Monitoring } \\
\text { and validation of change }\end{array}$ \\
\hline Setting goals for change. & 0.916 & \\
Define tasks and dependencies. & 0.893 & \\
Assign resources and produce & 0.918 & \\
equipment/materials. & 0.716 & \\
Perform change/tasks. & 0.824 & \\
Implement change into production. / Return to & 0.927 & 0.887 \\
service. & & 0.917 \\
Formulate high level plan. & & 0.802 \\
Update CMDB / Asset repository & & 0.772 \\
Obtain approval to proceed. & & 0.821 \\
Define success criteria. & & \\
Validate completed change. & & \\
Document discrepancies. & & \\
\hline
\end{tabular}

Source. Authors' own research 
Table 9 contains the eigen values of the factors and the percentage of explained variance. The results of the factor analysis suggested that the applied measurement scales had the properties of convergent and discriminant validity, given that the corresponding claims had a high factor load on only one factor and low factor loads on the other factor.

Table 9.

Eigen values and percentage of explained variance (change management in ICT sector)

\begin{tabular}{ccccc}
\hline Factor & Eigen value & Cumulative eigen value & $\begin{array}{c}\text { Percentage of } \\
\text { explained variance }\end{array}$ & $\begin{array}{c}\text { Cumulative percentage } \\
\text { of explained variance }\end{array}$ \\
\hline 1 & 4.900 & 4.900 & 44.542 & 44.452 \\
2 & 4.029 & 8.929 & 36.626 & 81.168 \\
\hline
\end{tabular}

Source. Authors' own research

For testing hypotheses using multiple linear regression, the variable "Change Management" was created by summing the results of respondents on both factors of change management in the ICT sector, where the results are weighted by the share of each factor in the total explained variance.

Table 10.

Descriptive statistics of variable "Change Management"

\begin{tabular}{cccccccc}
\hline Variable & N & Arithmetic mean & Min. & Max. & Std. deviation & Skewness & Kurtosis \\
\hline Change Management & 103 & 25.0058 & 9.20 & 27.75 & 3.09670 & -2.298 & 8.358 \\
\hline
\end{tabular}

Source. Authors' own research

Table 10 shows that the values of the asymmetry coefficient (Skewness) and the roundness coefficient (Kurtosis) were within the limits of acceptability. The absolute value of the asymmetry coefficient was less than $+/-3$, and the roundness coefficient was less than 10 . Since the collected data did not show an unacceptable level of univariate normality, the variable "Change Management" was used in further analyses.

Hypothesis testing was performed by multiple linear regression to predict the dependent variable based on the comprehension obtained from a series of independent variables and to determine the nature of the relationship between these variables. Quantitative scales were used to measure the variables. The standard method of multiple linear regression was used such a way that all independent variables entered the regression equation simultaneously, with the aim of investigating the relationship between the whole set of independent variables and the dependent variable. Regression coefficients and a t-test were used to evaluate the strength of the relationship between the variables.

\section{Research Findings}

To test the hypothesis that organizational changes positively impact change management, was performed multiple linear regression, where the factors of organizational changes (ORGP_1 and ORGP_2) served as predictors (independent variables) in the model. Both variables showed the characteristics of univariate normality in the descriptive analysis. 
Table 11.

Multiple regression results (organizational change / change management in ICT sector)

\begin{tabular}{lcccc}
\hline $\mathbf{N}=103$ Variable & Coefficient & Standard deviation & t (101) & p-level \\
\hline$\alpha$ & 17.619 & 1.856 & 9.495 & 0.000 \\
ORGP_1 & 0.547 & 0.288 & 1.901 & 0.060 \\
ORGP 2 & 0.864 & 0.405 & 2.132 & 0.035 \\
\hline Statistics & Value & & & \\
\hline Multiple R & 0.377 & & & \\
Multiple R2 & 0.142 & & & \\
Adjusted R2 & 0.125 & & & \\
F(2.100) & 8.281 & & & \\
p & 0.000 & & &
\end{tabular}

Source. Authors' own research

According to the results of multiple linear regression conducted by the method of least squares (Table 11), the equation of the model of the impact of organizational change on change management in ICT sector can be estimated. The results also show that the influence of the ORGP_1 factor is not statistically significant, so the equation can alternatively be estimated only by the constant and the ORGP_2 factor: $\bar{Y}=17,619+0,864 *$ ORGP_2

The results of multiple linear regression led to the conclusion that there is a positive and statistically significant impact of organizational change on change management in ICT sector, so the following research findings can be given:

1. Organizational changes positively and statistically significantly impact change management in ICT sector $(\mathrm{F}(2,100)=8,281, \mathrm{p}<0.000)$.

2. Encouraging organizational change has a positive, but not statistically significant effect on change management in ICT sector $(\beta 1=0.547, p>0.05)$

3. Reinforcement organizational change has a positive and statistically significant effect on change management $(\beta 2=0.864, p<0.04)$

The hypothesis of this empirical study: "Organizational change has a positive impact on change management in ICT sector" was proven $(\mathrm{p}<0.000)$. The analysis of the results of this empirical research showed that encouraging change in the organization has a positive effect on change management in ICT sector but it is not statistically significant ( $p>0.05)$, so it is possible to conclude that encouraging organizational change has an important role in change management in ICT sector. Also, according to the results of the analysis, reinforcement of organizational changes has a positive and statistically significant $(p<0.04)$ impact on change management in ICT sector in the Republic of Croatia so it can be considered as the most important segment of ADKAR model in Croatian ICT organizations.

As both managers and employees participated in this empirical research, additional tests were conducted to determine the difference in attitudes towards organizational change between managers and employees. A t-test on organizational change factors was performed, considering the results of Levene's Test for Equality of Variances. The results of the analysis are shown in Table 12 .

Table 12.

Differences in attitudes of managers and employees on the factors of organizational change

\begin{tabular}{lcccc}
\hline \multicolumn{1}{c}{ Organizational change factors } & $\begin{array}{c}\text { Arithmetic mean } \\
\text { (managers) }\end{array}$ & $\begin{array}{c}\text { Arithmetic mean } \\
\text { (employees) }\end{array}$ & t(101) & p-level \\
\hline Encouraging organizational change & 5.6419 & 5.7106 & -0.277 & 0.782 \\
Reinforcement organizational change & 5.1450 & 4.8586 & 1.499 & 0.154 \\
\hline
\end{tabular}

Source. Authors' own research 
The results in Table 12 show that there is no difference in attitudes towards organizational change between managers and employees. The difference in attitudes on any factor of organizational change did not achieve statistical significance $(p>0.05)$.

\section{Conclusions}

Due to the rapid technological development and especially the development of information and communication technologies, as well as the increasingly pronounced indicators of the process of globalization, the modern economy is abandoning the processes characteristic to the classical economy and turning to the digital economy. While the classical economy is based on the management of material resources, the digital economy finds its foundation in the management of intellectual capital resources. The ICT sector in the digital economy is not only becoming a central point without which modern business is unthinkable, but also the central point of economic growth. Organization of working processes, management, and decision-making in the digital economy are characterized by a rapid and dynamic change and a thoughtful response to it in order to achieve profit growth. In modern business, a successful change management strategy is the only way for an organization to survive in an environment where there are more and more competitors every day.

Organizational change is a very complex question for every organization and needs to be understood to manage this change effectively. Organizational change is very important for all employees because it determines the work processes, work environment and social relations between employees as well as between employees and their managers. It is also extremely important for managers and has a great role in motivating implementation and monitoring change. Organizational change is especially important for organizations in ICT sector because effective organizational change management is the key to business success. Without constant change and adaptation to the requirements of a dynamic environment, organizations in ICT sector cannot survive.

Variables that give unique importance in predicting the impact of organizational change to change management in ICT sector in the Republic of Croatia are encouraging organizational change and reinforcement organizational change. This empirical research confirmed that encouraging organizational change has a positive but not statistically significant effect on change management, while reinforcement organizational change has a positive and statistically significant effect on change management in ICT sector. Also, organizational change has a positive and statistically significant effect on change management. That is why is important to understand the benefits organizations have from organizational change. This is achieved through an analysis of the success and the prediction of future sector developments in the country's overall economy. The importance of change management, especially reinforcement organizational change, should be understood through the importance of survival in market competition, so creating and maintaining a competitive advantage can be understood as a rapid and continuous adaptation to dynamic and changing market circumstances. How an organization will implement organizational change depends on managerial decisions and business strategies, which is a highly intellectually demanding process based on knowledge and experience.

The results of this empirical research confirmed that encouraging change in the organization is important although not statistically significant, indicating that managing change in organizations in the ICT sector requires an evolutionary approach to achieve the desired results. The findings of this study support the attitude that the strategy of change management is very important to achieve a successful reorganization of work processes in ICT sector. To gain success in this step, it is necessary to encourage organizational change through reactive action not only related to the new market conditions but also to attitudes related to organizational change and its implementation in work processes. Adaption to 
change and gained business success should be the results of the change management implemented by a successful organization. Therefore, the model in this empirical research undoubtedly provides evidence of how encouraging organizational change and reinforcement organizational change as the strongest part of ADKAR model have a positive impact on change management in ICT sector in the Republic of Croatia. In this way, change management is one of the most important and unavoidable parts of modern business. Also, these results upgrade and complement previous research on the impact of organizational change on change management and provide undoubted evidence of a possible model for change management in ICT sector in the Republic of Croatia. A representative sample of this research provides sufficient elements to establish a quality methodological model of change management and monitor the impact of organizational change on change management in ICT sector. The final result of the model derived from this empirical research confirms that organizational change has a positive impact on change management in the ICT sector.

\section{Acknowledgement}

This paper was presented at the $3^{\text {rd }}$ International Conference on Management, Economics and Finance, 26.-28 $8^{\text {th }}$ Feb, 2021, Amsterdam, Netherlands

\section{References}

Addy R. (2007). Effective IT service management to ITIL and Beyond, New York, USA:Springer

Burnes B. (2004). Managing Change: A Strategic Approach to Organisational Dynamics, 4th ed. Harlow, USA: Prentice Hall.

European Commision, Predict 2018 (January 2019). ICT Sector Analysis 2018. [Online]. Available: http://www.halcyon.com/pub/journals/21ps03-vidmar

Hiatt J.F. (2006). ADKAR. A Model for Change in Busienss Government and Our Community. How to Implement Successful Change in Our Personal Lives and Professional careers. Loveland, USA: Prosci Inc.

Morgan, J. W., Brightman, B. K. (2001). „Leading organizational change,“ Career Development International, vol. 6(2), pp. 111-118.

Prosci Inc. (2017). Change Management Process. [Online]. Available: https://www.prosci. com/resources/articles/change-management-process

Prosci Inc. (2017). The ADKAR model as a common language for change. USA: Prosci Inc.

Schütte R. (1998). Grundsätze ordnungsmäßiger Referenzmodellierung - Konstruktion konfigurations- 7 und anpassungsorientierter Modelle. Wiesbaden: Gabler

Senior B. (2002). Organisational Change, 2nd ed. London, U.K.:Prentice Hall

Tudor, L. (2014). „Change Management - Challenge And Opportunity For Sustainable Developmnet Of Romanian Companies“. Proceedings of the International Management Conference, Faculty of Management, Academy of Economic Studies. Bucharest, Romania, pp. $466-476$

Varkey P., Antonio K. (2010). „Change Management for Effective Quality Improvement: A Primer," American Journal of Medical Quality, vol. 25(4), pp. 268-273

White S. K. and Greiner L., CIO (January 2019). What is ITIL? Your Guide to the IT Infrastructure Library. [Online]. Available: https:/www.cio.com/article/2439501/ infrastructure-it-infrastructure-library-itil-definition-and-solutions.html 